Lastly, all the studies we have reviewed were intervention studies in the format of in vitro or ex vivo, thus 'one's behaviour, lifestyle, diet, genetic make-up, oral hygiene, and access to professional dental care' could not have affected the results. In addition, there is overwhelming evidence that industrial exposure to acid fumes causes dental erosion..$^{6,7}$ Therefore, it is transparent that exposure to acids is a risk factor for dental erosion. ${ }^{8,9}$

In conclusion, we do not discount the benefits of polyols on dental caries but acidic additives should be avoided and long term safety of polyols should be studied in humans. The objective of our review was to raise awareness of the risk hidden under the false security of 'sugar-free' dental health claims.

1. Nadimi H, Wesamaa H, Janket SJ, Bollu P, Meurman $J \mathrm{H}$. Are sugar-free confections really beneficial for dental health?Br Dent J 2011;211: E15.

2. Bloomgarden Z T. Nonnutritive sweeteners, fructose, and other aspects of diet. Diabetes Care 2011; 34: e46-51

3. Blundell J E, Hill A J. Paradoxical effects of an intense sweetener (aspartame) on appetite. Lancet 1986; 1: 1092-1093.

4. Nettleton J A, Lutsey $P L$, Wang Y, Lima J A, Michos $E D$, Jacobs $D R$, Jr. Diet soda intake and risk of incident metabolic syndrome and type 2 diabetes in the Multi-Ethnic Study of Atherosclerosis (MESA). Diabetes Care 2009; 32: 688-694.

5. Janket S-J, Baird A E, Chuang S-K, Jones J A. Metaanalysis of periodontal disease and risk of coronary heart disease and stroke [see comment]. Oral Surg Oral Med Oral Pathol Oral Radiol Endod 2003: 95: 559-569.

6. Chikte U M, Josie-Perez A M, Cohen T L. A rapid epidemiological assessment of dental erosion to assist in settling an industrial dispute. J Dent Assoc S Afr 1998; 53: 7-12

7. Fukayo S, Nonaka K, Shinozaki T, Motohashi M, Yano T. [Prevalence of dental erosion caused by sulfuric acid fumes in a smelter in Japan]. Sangyo Eiseigaku Zasshi 1999;41: 88-94.

8. Hughes J A, West NX, Parker D M, van den Braak $\mathrm{MH}, \mathrm{Addy} \mathrm{M}$. Effects of $\mathrm{pH}$ and concentration of citric, malic and lactic acids on enamel, in vitro. Dent 2000;28: 147-152.

9. Petersen PE, Gormsen C. Oral conditions among German battery factory workers. Community Dent Oral Epidemiol 1991; 19: 104-106.

DOI: 10.1038/sj.bdj.2011.1059

\section{ASTONISHING DENIAL}

Sir, I would like to draw readers' attention to the serious issue of 'big' corporate takeover of dentistry. In my opinion, the denial of the profession and the BDA to confront this matter is astonishing. My personal experience when discussing the topic with the colleagues who had the pleasure of working for the major corporates is that it has been overwhelmingly negative.
Please let's not fool ourselves: a corporate's main function is to generate money for its shareholders. It is not the principal dentist safeguarding the patients' best interests or introducing the latest and the best for 'his or her' practice.

With regard to the free market, there is no free market regulating the market. Currently there are few estate agents dealing with dental practice sales. Incidentally these agents deal initially with the best rewarding clients.

of course the NHS has a fair tendering procedure for its allocation of new contracts. However, corporate resources will employ full-time staff to deal with tendering. Can 'Dr Smith' who has dedicated his life to NHS dentistry publish a 100 page tendering proposal? Not to mention the bank and the new CQC with its 'register first before buying' ingenious policy.

We may all be comfortable burying our heads in the sand for now. But be aware of the future. Would the strategy of a large supermarket chain entering dentistry be unusual for a corporate? Not at all. It is part of a genuine and legal growth strategy: squeeze suppliers and wages. What income would be allocated to a self-employed dentist working in such circumstances? I suppose a hard working farmer will be able to answer this with some degree of passion. And imagine if that chain owned and supplied all other small practices with dental material and other services.

D. Afshar Manchester DOI: 10.1038/sj.bdj.2011.1060

\section{SCURVY AND THE AGEING POPULATION}

Sir, we write to you about two cases of scurvy which recently presented to our unit. Despite a great reduction in its prevalence, this ancient disease still affects people in our developed world today. It is noteworthy that the Care Quality Commission has recently published a report showing 17\% of hospitals investigated were not compliant in meeting the nutritional needs of patients. ${ }^{1}$ Furthermore, studies have shown that high proportions of elderly people already have low vitamin C levels on medical admission. ${ }^{2}$
The earliest symptom of scurvy, occurring only after many weeks of deficient intake, is fatigue. The most common cutaneous findings are perifollicular haemorrhages, ecchymoses, leg oedema, poor wound healing, and coiled body hairs. Gingival abnormalities include gingival swelling, purplish discoloration, and haemorrhages. Pain in the back and joints is common. Syncope and sudden death may occur. ${ }^{3}$ Scurvy is easily treated with vitamin C supplements and the inclusion of fresh fruit and vegetables in a daily diet. ${ }^{4}$

An 83-year-old female who lived in a care home was referred regarding 'erosions' in her mouth with associated difficulty in maintaining adequate nutritional intake. The patient's medical history included coronary artery bypass graft, stroke, nephrectomy, anaemia, osteoarthritis and dementia. There were no known allergies or use of alcohol and the patient had stopped smoking 40 years ago.

Clinical examination revealed blood crusted lips and generalised confluent ulceration affecting the buccal mucosa which also involved the gingiva. An elevated blood urea was noted, suggestive of renal dysfunction or poor fluid intake and her vitamin $\mathrm{C}$ levels were low. Clinical symptoms coupled with low ascorbic acid levels led to a diagnosis of scurvy. The patient was started on vitamin $\mathrm{C}$ supplements and a review a week later showed complete resolution of the oral lesions.

In another case, a 63-year-old female presented reporting a one month history of poor eating with reported weight loss due to swollen and bleeding gums. There was no relevant medical or social history except for a diet consisting mainly of plain pasta, devoid of fresh fruit and vegetables.

Clinical examination revealed the gingiva were swollen and bled spontaneously or on minor trauma (Fig. 1). All teeth were mobile. Initial blood tests revealed a $\mathrm{Hb}$ 7.9/dl and an otherwise normal FBP and coagulation screen. Medical examination revealed dependent oedema of the lower legs with bruising, perifollicular haemorrhaging and corkscrew hairs, (Fig. 2). A diagnosis of scurvy with secondary anaemia 


\section{LETTERS}

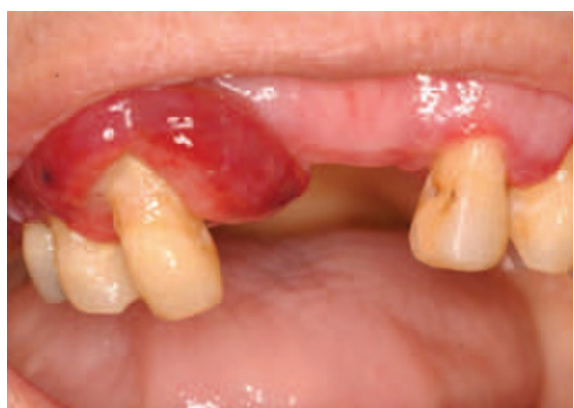

Fig. 1 The swollen gingiva

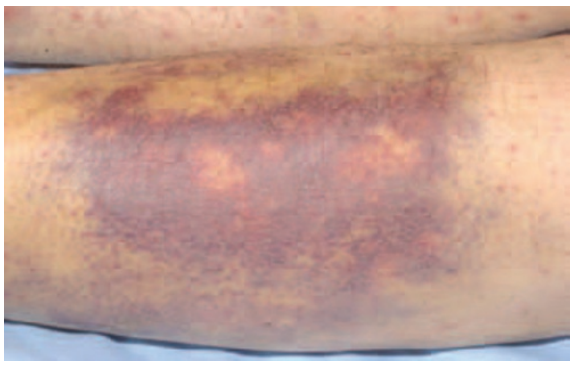

Fig. 2 Dependent oedema of the lower legs

was made. The patient was admitted for further investigations and vitamin C supplementation was commenced. No other intervention was needed. At a four week review weight had been gained and only mild gingival inflammation secondary to her underlying periodontal disease was present.

As the UK's population is ageing, with increasing numbers residing in care homes, we feel it is important for clinicians to be aware that scurvy could be affecting our patients and particularly those who may be visited on a domiciliary basis.

$$
\begin{array}{r}
\text { J-M. Chapman, J. J. Marley } \\
\text { Belfast }
\end{array}
$$

1. Care Quality Commission. Dignity and nutrition inspection programme: national overview. October 2011. Available at: http://www.cqc.org.uk/_db/_ documents/20111007_Dignity_and_nutrition_ inspection_report_FINAL.pdf.

2. Hirschmann J V, Raugi G J. Adult scurvy. J Am Acad Dermatol 1999; 41: 895-909.

3. Richardson T I L, Ball L, Rosenfeld T. Will an orange a day keep the doctor away? Postgrad Med J 2002; 78: 292-294.

4. Halligan T J, Russell N G, Dunn W J, Caldroney S J, Skelton T B. Identification and treatment of scurvy: a case report. Oral Surg Oral Med Oral Pathol Oral Radiol Endod 2005; 100: 688-692.

DOI: 10.1038/sj.bdj.2011.1061

\section{INWARD DENTAL TOURISM}

Sir, dental tourism has been a controversial subject in the UK in recent years. Although statistics for the number of UK residents travelling overseas for dental treatment are not officially collated, media reports have suggested that an increasing number of individuals are pursuing this option. That impression has been echoed by the BDA's own research, which has identified a significant number of patients travelling to countries including Hungary and Poland for procedures, and needing attention for complications after returning to the UK.

That need for after care and the concerns it raises have left UK dentists lamenting the choices individuals have made and the BDA has consistently warned patients to think very carefully before deciding to go overseas. But it's not just practitioners in the UK who have reservations about UK citizens going overseas for care. Members of the BDA's Middlesex and Hertfordshire Branch, on a recent trip to Budapest, heard from Dr Jolán Bánóczy, Professor Emeritus at the Department of Oral Biology, Semmelweiss University of Medicine in Budapest, how homegrown Hungarian dentists view inward dental tourism in their country. Dr Bánóczy discussed dental tourism at some length, which aroused a good deal of interest from the audience. She personally did not agree with it, as after care is usually impossible. Dentists in Hungary obviously share the reservations of colleagues in the UK about dental tourism. The Hungarian Dental Association will give no opinion on the matter, but the government is in favour because it brings much-needed foreign currency into the country.

Dr Bánóczy also highlighted the possibility of dentistry becoming more commercial if the number of overseas visitors continues to increase, being concerned that if Hungarian dentists are concentrating on treating patients from overseas, there may be an adverse impact on oral health provision for the Hungarian population. Although Hungary has four dental schools producing in the region of 220 graduates a year, the oral health challenges they present are significant and Dr Bánóczy explained that Hungary faces high rates of decay in rural areas, is one of the worst countries for rates of mouth cancer and must face the same demographic challenge as the UK: an ageing population.
Witnessing wise words on an international stage provided Branch members with food for thought.

\section{B. Arends}

By email

DOI: 10.1038/sj.bdj.2011.1062

\section{UPDATED RESOURCE FOR DRUG PRESCRIBING}

Sir, I would like to draw your readers' attention to the second edition of Drug prescribing for dentistry, a publication by the Scottish Dental Clinical Effectiveness Programme (SDCEP). Released in August 2011, this resource has been written by a small group of clinicians with a particular interest in prescribing.

Specifically applicable to primary care dental professionals, it provides fully updated guidance, presented in a user-friendly, ring-binder format. The updated edition improves on its predecessor by a new divider-style design separating the ten chapters to allow ease of navigation. Extra sections on adverse drug reactions and labelling are incorporated along with more detailed information on the treatment of medical emergencies in dental practice to include milder forms of allergy, acute coronary syndromes, and stroke. Also included is a useful section on recommendations for self audit to improve the quality of drug prescribing in dentistry.

Designed to be a handy resource to be used in conjunction with the British National Formulary (which contains the Dental Practitioners Formulary), information has been collated from the BNF (BNF 61), BNF for Children (BNFC 2011), and a wide variety of clinical and product literature including guidance from professional bodies.

Although it is a Scottish publication, this guidance is also available electronically via the SDCEP website http:// www.sdcep.org.uk/index.aspx?o=2334 and plans are in hand to develop a Smartphone app.

\section{N. E. O'Murchu} Glasgow 